\title{
Facile Synthesis of Silica Composites with Oil Sorption Efficiency from a Vital Agricultural Waste of Corn Stalk Cultivated in Bishoftu, Ethiopia
}

\author{
M. Kamaraj $\mathbb{D}^{1},{ }^{1}$ Sudarshan Kamble $\mathbb{D}^{2},{ }^{2}$ and S. V. R. K. N. Sonia $\mathbb{D}^{2}$ \\ ${ }^{1}$ Department of Biotechnology, College of Biological and Chemical Engineering, Addis Ababa Science and Technology University, \\ Addis Ababa 16417, Ethiopia \\ ${ }^{2}$ Department of Civil Engineering, College of Architecture and Civil Engineering, Addis Ababa Science and Technology University, \\ Addis Ababa 16417, Ethiopia
}

Correspondence should be addressed to M. Kamaraj; drkamarajm@gmail.com

Received 26 August 2021; Revised 6 September 2021; Accepted 22 September 2021; Published 6 October 2021

Academic Editor: Silvano Mignardi

Copyright (c) 2021 M. Kamaraj et al. This is an open access article distributed under the Creative Commons Attribution License, which permits unrestricted use, distribution, and reproduction in any medium, provided the original work is properly cited.

This study is attempted to extract the amorphous silica composites using the combined $\mathrm{HNO}_{3}$ leaching-calcination $\left(600^{\circ} \mathrm{C} / 6 \mathrm{~h}\right)$ method from corn stalk harvested in Bishoftu, Ethiopia, owning to its profuse dumping, less cost, and negative environmental implications. The resultant composite characteristics such as amorphous nature are connected via the grain boundary which produces an agglomerated structure that has a disordered morphology, and the presence of siloxane and silanol groups, as well as additional functional groups, is reported. The synthesized product is applied in the removal of oil from synthetic oily wastewater (SYOWW) using batch mode delivering a maximum oil removal of up to $99 \%$. The outcome of the study features the potential acclimatization of the Ethiopian corn stalk as a substitute precursor for the production of silica composites which has a potential oil adsorption capacity that can be used for oil spill cleanup.

\section{Introduction}

Conversion of agroindustrial solid wastes produced on a large scale to value-added products is a key challenge for sustainable and green chemistry approaches in the circular economy concept. Creative and innovative conduct to reduce the waste, impacts, and environmental contamination sourced by their indiscriminate disposal has been targeted in the $21^{\text {st }}$ century [1]. Corn, among other agroindustrial byproducts, has rapidly expanded and altered Africa's farming methods as the most significant food crop. Corn is widely planted in Ethiopia, and its area is still growing faster than any other crop. According to a study conducted by Ethiopia's Central Statistical Agency, 7.1 million hectares of corn cropping were apprehended at the national level in 2010. [2]. It was 971 thousand tonnes in 1971 and expanded to 8600 thousand tonnes in 2020 with $7.60 \%$ of an average annual growth rate. The leftover corn stalks are classified as trash and disposed of in large quantities in a landfill after harvesting and burning. The chemical components in the corn stalk are transformed into combustible gases like methane, carbon monoxide, hydrogen, and ash [3] when they are burned, causing deterioration consequences.

Material scientists are paying close attention to silica $\left(\mathrm{SiO}_{2}\right)$ because of its widespread use in a variety of fields, including the creation of a new class of material, solar energy systems, and water purification $[4,5]$. Various agricultural wastes are used as reinforcement in the creation of silica composites $[3,6,7]$. However, literature on the extirpation of silica from the Ethiopian corn stalks is very limited [8]. Sodium silicate acidification by reacting materials containing silica is a common silica synthesis method that consumes a lot of energy. As a requirement, developing a simple, lowcost, and low-energy mode for silica development from agroindustrial waste would be advantageous [9]. Hence, the current research is centered on extracting silica composites 


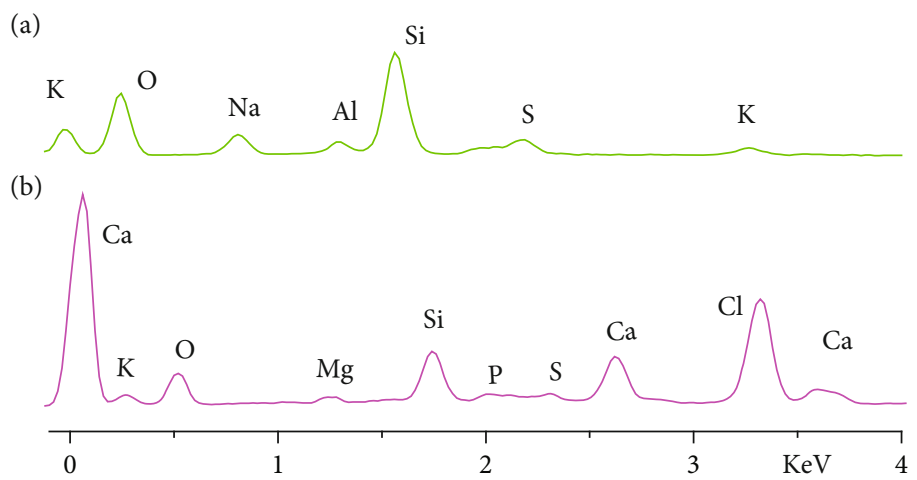

Figure 1: EDS analysis of (a) CSSC and (b) CS ash.

from Ethiopian maize stalks as a value-added product with oil adsorption capacity.

\section{Methodology}

Corn stalks (CS) were obtained from an Ethiopian agricultural area in Bishoftu. After successive washing using tap water to remove the physically adhered impurities, CS was dried in an air-circulated oven at $100 \pm 2^{\circ} \mathrm{C}$ for $12 \mathrm{~h}$. The dried CS was chopped by an electric grinder into small pieces for auxiliary treatment. Silica synthesis was performed by acid $\left(1 \mathrm{~N} \mathrm{HNO}_{3}\right)$ leaching under the boiling condition for $1 \mathrm{~h}$ followed by thorough washing with warm distilled water to remove acid and then calcination in an electric furnace at $600^{\circ} \mathrm{C}$ for $6 \mathrm{~h}$, as depicted by Ghorbani et al. [9]. The resultant material of corn stalk silica composite (CSSC) was further characterized by energy-dispersive X-ray spectroscopy (EDS) coupled with scanning electron microscopy (SEM) instrument (JSM 6360, JEOL, Japan), X-ray diffraction (XRD) (X-Pal PRO, Pan Analytical, The Netherlands), and Fourier transform-infrared (FTIR) spectrometer (Spectrum, PerkinElmer, USA) [8].

The preparation of SYOWW was done according to Shoba et al. [10] and Izevbekhai et al. [11]. To achieve a homogeneous SYOWW solution, various concentrations $(100,200,400,600,800$, and $1000 \mathrm{mg})$ of vacuum pump oil (Mobil, USA) and sodium dodecyl sulfate $(0.01 \mathrm{~g})$ were added to $1 \mathrm{~L}$ of distilled water and sonicated (probe sonication) for $15 \mathrm{~min}$ at $75 \%$ amplitude. This SYOWW was utilized in a batch mode for the oil adsorption experiment, with a variable amount (1-5 mg) of adsorbent (CSSC) placed in an emptied tea bag. After sealing the teabag with a plastic sealer and placing it in $50 \mathrm{~mL}$ of SYOWW (100-1000 mg/L), it was left undisturbed for a predetermined amount of time (24h). An empty tea bag without CSSC has been used as a control. After treatment, UV-Vis spectroscopy was used to determine the absorbance of the samples, and the oil removal efficiency (\%) was calculated as follows [11]:

$$
\operatorname{Removal}(\%)=\left[\frac{\left(O_{\mathrm{i}}-O_{\mathrm{f}}\right)}{O_{\mathrm{i}}}\right] \times 100 \text {, }
$$

where $O_{\mathrm{i}}$ and $O_{\mathrm{f}}$ are the optical density (OD) values corresponding to initial oil concentration and final oil concen-
TABLE 1: Elemental composition of CS ash and CSSC by EDS analysis.

\begin{tabular}{lcc}
\hline Element & CS ash & Weight (\%) \\
\hline Oxygen (O) & 46.98 & CSSC \\
Silicon (Si) & 9.04 & 39.18 \\
Sulfur (S) & 1.04 & 48.24 \\
Potassium (K) & 27.96 & 2.33 \\
Sodium (Na) & - & 1.29 \\
Aluminum (Al) & - & 6.97 \\
Calcium (Ca) & 2.29 & 1.99 \\
Magnesium (Mg) & 1.51 & - \\
Phosphorus (P) & 0.95 & - \\
Chlorine $(\mathrm{Cl})$ & 10.24 & - \\
\hline
\end{tabular}

tration after the adsorption treatment. The mean average and standard errors were calculated from the technical triplicates of the experiments.

\section{Results and Discussion}

The CSSC produced by calcination at $600^{\circ} \mathrm{C}$ was found as a white-colored powder. Temperature optimization study was conducted by Ghorbani et al. [12] for silica production from plant biomass and suggested that $600^{\circ} \mathrm{C}$ for $6 \mathrm{~h}$ was the optimal condition for silica extraction. Hence, the specific temperature $\left(600^{\circ} \mathrm{C}\right)$ and time $(6 \mathrm{~h})$ for calcination are used as constant operating conditions in this work. Plant biomass leaching with an acidic solvent prior to calcination has been proven to be an effective strategy for removing significant metallic impurities, resulting in the creation of ash that is practically white in color $[9,13]$, and the same is obtained in this investigation. EDS analysis (Figure 1(a)) revealed that CSSC is in a composite manner with the silica as a major element (48.24 wt \%) along with other elements of $\mathrm{O}, \mathrm{Na}, \mathrm{Cl}, \mathrm{S}$, and K. EDS analysis (Table 1, Figure 1) reported a decrease of impurities (chlorine, phosphate, etc.) and an increase in silicon ( $\mathrm{Si}$ ) content $(9.04 \%$ to $48.24 \%$ ) in comparison to the CS ash (Figure 1(b)), which is produced by calcinating $\left(600^{\circ} \mathrm{C} / 6 \mathrm{~h}\right) \mathrm{CS}$ without $\mathrm{HNO}_{3}$ leaching. This could be related to the elimination of several soluble components 


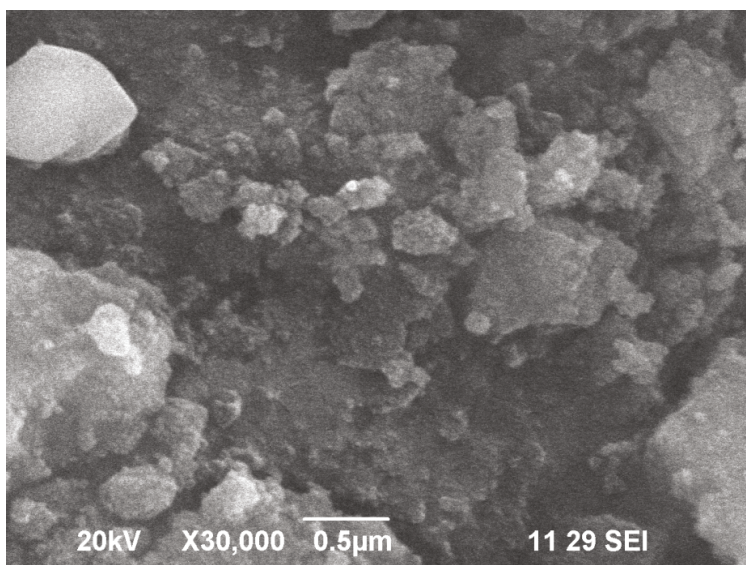

Figure 2: SEM image of CSSC.

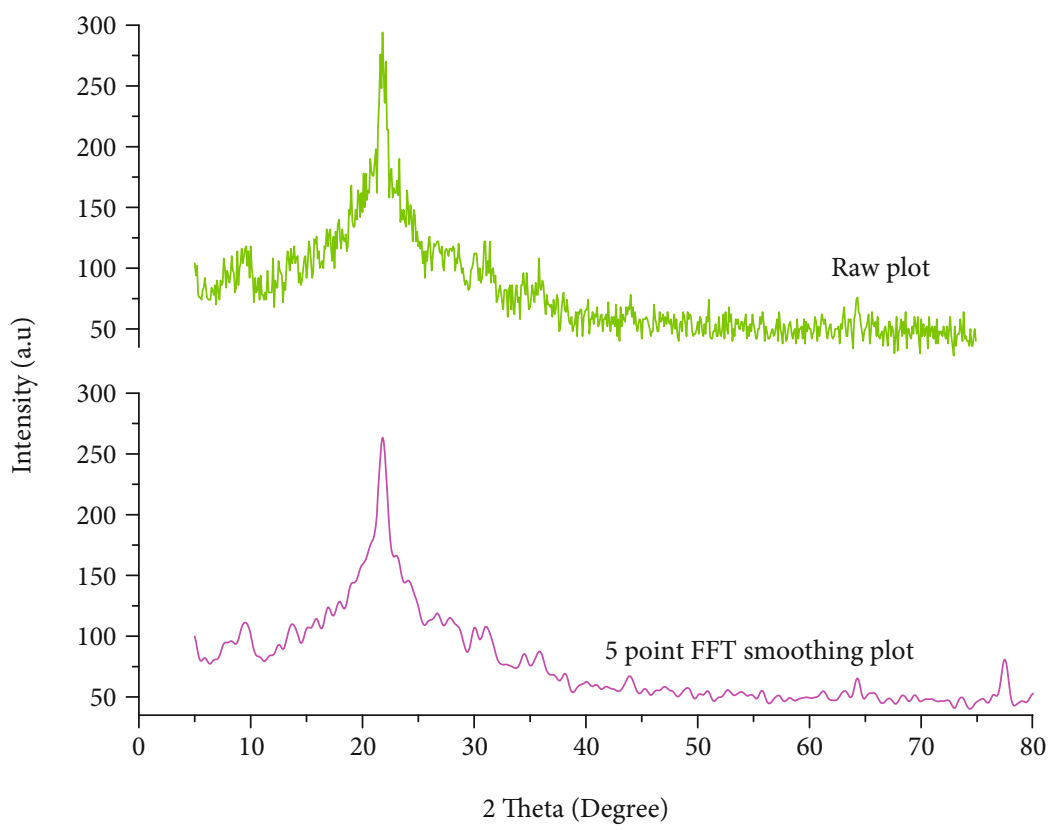

FIGURE 3: XRD pattern of CSSC.

from CS during $\mathrm{HNO}_{3}$ pretreatment, like as cellulose and hemicellulose. SEM image (Figure 2) of CSSC divulged that the morphology has no definite shape and the individual particle's size is intricate to measure because of their agglomeration. The particles have a tendency to accumulate rapidly on the powdery surface due to the silica's nonconductive nature to form an agglomeration [14]. As a result, it was predicted at random that the particle sizes would range from nano to micron, which is consistent with the literature [15, $16]$.

The organic material that contains silicon in a high percentage can generate crystalline or amorphous silica by the burning process [1]. The XRD diffraction pattern of CSSC (Figure 3) exhibited a hill-like peak around $2 \theta=15-30^{\circ}$ which is relative to highly disordered silica. The other salts are detected in the XRD pattern as impurities in addition to silica, and it is possible that various insoluble salts are retained in the filtration process by adhering to silicon parti- cles. According to the literature, escalating high temperatures $\left(>600^{\circ} \mathrm{C}\right)$ cause amorphous silica to crystallize into cristobalite and/or tridymite. Because silica is rendered inert in its crystalline form, such crystallization is a disadvantage in the creation of silicon-based products [17]. This issue is circumvented in this study by burning CS at $600^{\circ} \mathrm{C}$ to reduce the unburned carbon and retain the amorphous silica.

FTIR analysis was used to identify the primary functional groups contained in the CSSC, as shown in Figure 4. The wide peak in the $3410-3470 \mathrm{~cm}^{-1}$ range is caused by the $\mathrm{O}-\mathrm{H}$ bond stretching vibration created by the silanol $(\mathrm{O}-\mathrm{H})$ groups, which could be owed to moisture that is absorbed on the surface of silica. The Si-O-Si (bending, symmetric, and asymmetric) groups are attributed in the region from 400 to $1300 \mathrm{~cm}^{-1}$. The production of sodium silicate is also confirmed by the presence of a peak at $1390 \mathrm{~cm}^{-1}$. The findings are consistent with those reported by earlier researchers $[3,5,9]$. The water molecule absorbed on the 


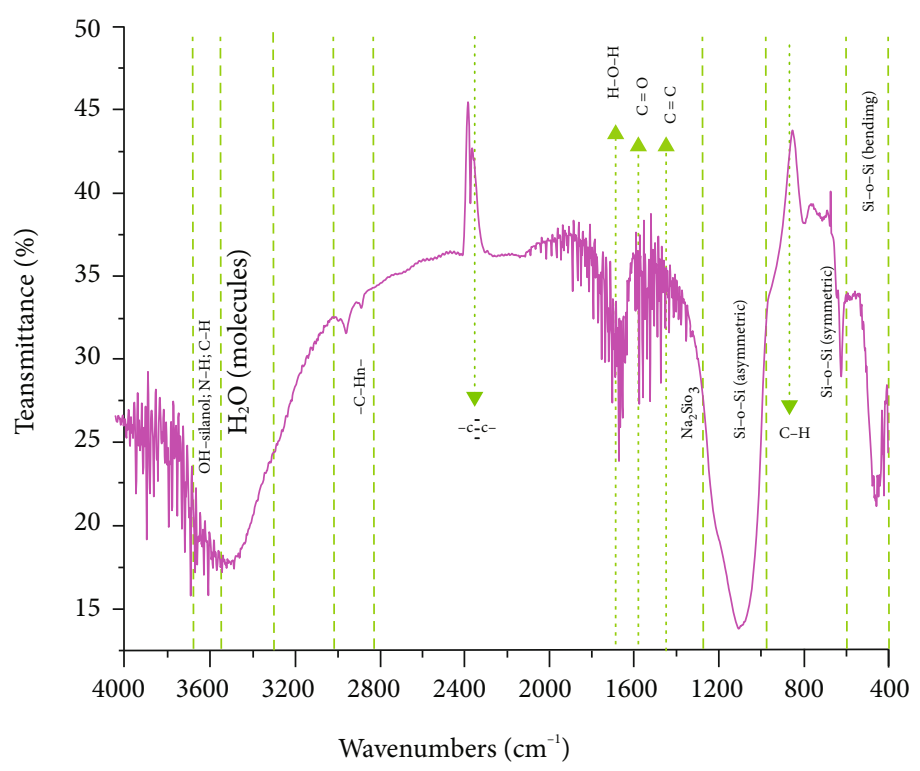

FIGURE 4: FTIR spectra of CSSC.

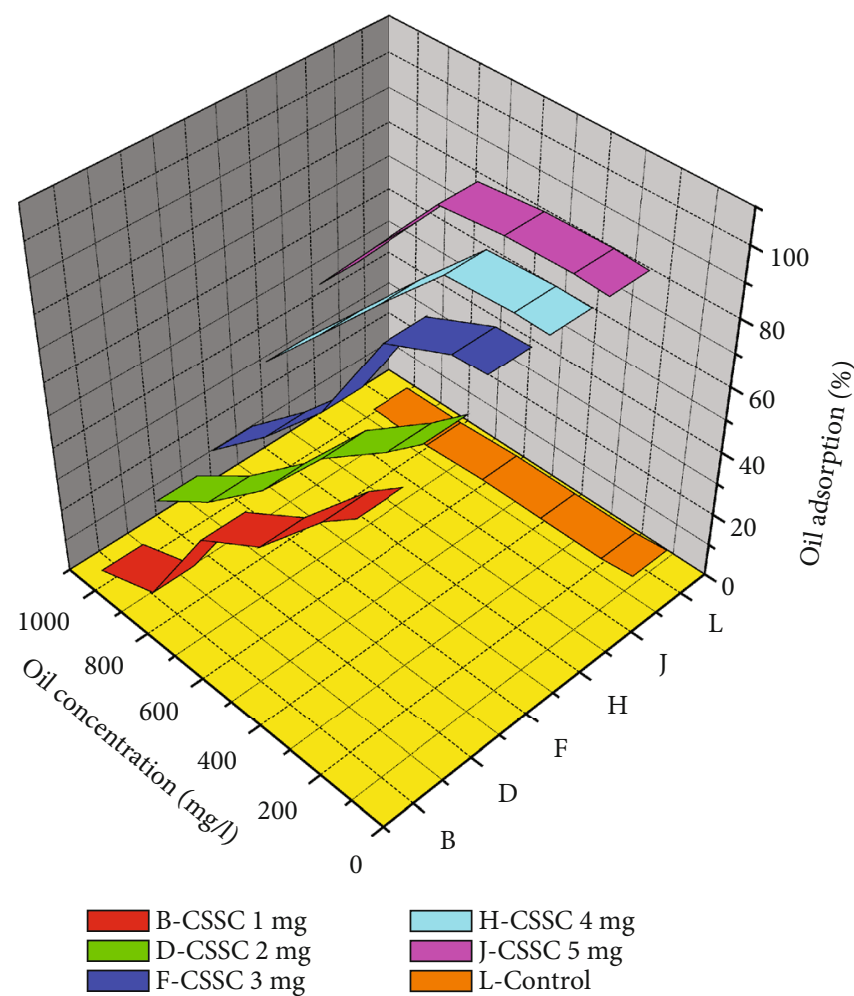

FIgURE 5: Oil removal efficiency of CSSC from SYOWW.

silica is evident in the $\mathrm{H}-\mathrm{O}-\mathrm{H}$ bending vibration by a peak around $1650 \mathrm{~cm}^{-1}$. The literature stated that the surface $\mathrm{OH}$ group can be easily produced during the contact of silica with the atmosphere $[18,19]$.

As seen from Figure 5, adsorption (\%) increased steadily up to $99 \%$ for the oil concentration from 100 to $600 \mathrm{mg} / \mathrm{L}$ and it subsequently reduced to $92 \%$ and $87 \%$ for the oil concentration of 800 and $1000 \mathrm{mg} / \mathrm{L}$, respectively, which was the maximum with a further increase in adsorbent (CSSC) dos- age from 1 to $5 \mathrm{mg} / \mathrm{L}$. The mild removal was observed in control which might be due to the adsorption/absorption behavior of an empty tea bag. The oil droplets enter easily into the pores of the adsorbent when the initial oil content was lower; hence, it elevates the adsorption rate $[11,20]$. When oil concentration increases, it substantially makes the oil droplets equal the size of the adsorbent pores and create competition. Hence, there was a subsequent drop in adsorption efficiency at this condition. The percentage of 
adsorption increased marginally as the adsorbent dosage was increased. The introduction of new and additional binding sites on the adsorbents might be the cause of this observed trend $[11,21]$.

\section{Conclusion}

The $\mathrm{HNO}_{3}$ leaching and calcination $\left(600^{\circ} \mathrm{C} / 6 \mathrm{~h}\right)$ method will be a potential way to extract the silica from the corn stalk and also its impact on the attrition of salt and metal impurities in the resultant silica composite. The CSSC can be used as a potential adsorbent to remove the oil from synthetic contaminated water. This research outcome enlightens the possible waste oversights as well as encourages economic heterogeneity entrained on by the current corn waste management strategies in Ethiopia. However, further studies are needed to elucidate the comprehensive mechanism and performance of CSSC in the pollution remediation process.

\section{Data Availability}

Data are available from the corresponding author upon request.

\section{Conflicts of Interest}

The authors did not declare any conflict of interest.

\section{References}

[1] S. Rovani, J. J. Santos, P. Corio, and D. A. Fungaro, "Highly pure silica nanoparticles with high adsorption capacity obtained from sugarcane waste ash," ACS Omega, vol. 3, no. 3, pp. 2618-2627, 2018.

[2] J. Alwang, G. W. Norton, and B. Shiferaw, Improved maize varieties and poverty in rural Ethiopia key messages, American Chemical Society,, Washington, D.C., 2014.

[3] V. Vaibhav, U. Vijayalakshmi, and S. M. Roopan, "Agricultural waste as a source for the production of silica nanoparticles," Spectrochimica acta part A: Molecular and biomolecular spectroscopy, vol. 139, pp. 515-520, 2015.

[4] S. Affandi, H. Setyawan, S. Winardi, A. Purwanto, and R. Balgis, "A facile method for production of high-purity silica xerogels from bagasse ash," Advanced Powder Technology, vol. 20, no. 5, pp. 468-472, 2009.

[5] P. E. Imoisili, K. O. Ukoba, and T. C. Jen, "Green technology extraction and characterisationof silica nanoparticles from palm kernel shell ashvia sol-gel," Journal of Materials Research and Technology, vol. 9, pp. 307-313, 2020.

[6] S. Rangaraj and R. Venkatachalam, "A lucrative chemical processing of bamboo leaf biomass to synthesize biocompatible amorphous silica nanoparticles of biomedical importance," Applied Nanoscience, vol. 7, pp. 145-153, 2017.

[7] J. A. Adebisi, J. O. Agunsoye, S. A. Bello et al., "Green production of silica nanoparticles from maize stalk," Particulate Science and Technology, vol. 38, no. 6, pp. 667-675, 2020.

[8] M. Kamaraj, K. Sudarshan, S. V. R. K. N. Sonia, P. Chidambararajan, and A. Bekele, "Upgradation of maize stalk waste as an alternate agrarian raw material for the production of amorphous silica composites," Journal of Analytical and Applied Pyrolysis, vol. 151, article 104908, 2020.
[9] F. Ghorbani, A. M. Sanati, and M. Maleki, "Production of silica nanoparticles from rice husk as agricultural waste by environmental friendly technique," Environmental Studies of Persian Gulf, vol. 2, pp. 56-65, 2015.

[10] B. Shoba, J. Jeyanthi, and S. Vairam, Synthesis, characterization of cellulose acetate membrane and application for the treatment of oily wastewater, Taylor \& Francis, 2020.

[11] O. U. Izevbekhai, W. M. Gitari, N. T. Tavengwa, W. B. Ayinde, and R. Mudzielwana, "Application of synthesized acetylated silica in the remediation of oily wastewater," Journal of Taibah University for Science, vol. 14, no. 1, pp. 1033-1041, 2020.

[12] F. Ghorbani, Habibollah Younesi, Z. Mehraban, M. S. Çelik, A. A. Ghoreyshi, and M. Anbia, "Preparation and characterization of highly pure silica from sedge as agricultural waste and its utilization in the synthesis of mesoporous silica MCM-41," Journal of the Taiwan Institute of Chemical Engineers, vol. 44, no. 5, pp. 821-828, 2013.

[13] R. M. J. James and M. S. Rao, "Silica from rice husk through thermal decomposition," Thermochimica acta, vol. 97, pp. 329-336, 1986.

[14] P. Lu and Y. L. Hsieh, "Highly pure amorphous silica nanodisks from rice straw," Powder Technology, vol. 225, pp. 149155, 2012.

[15] E. A. Okoronkwo, P. E. Imoisili, S. A. Olubayode, and S. O. O. Olusunle, "Development of silica nanoparticle from corn cob ash," Advances in Nanoparticles, vol. 5, no. 2, pp. 135-139, 2016.

[16] J. A. Adebisi, J. O. Agunsoye, S. A. Bello et al., "Extraction of silica from cassava periderm using modified sol-gel method," Nigerian Journal of technological development, vol. 15, no. 2, p. 57, 2018.

[17] J. Payá, J. Monzó, M. V. Borrachero, A. Mellado, and L. M. Ordoñez, "Determination of amorphous silica in rice husk ash by a rapid analytical method," Cement and Concrete Research, vol. 31, no. 2, pp. 227-231, 2001.

[18] G. M. D. W. Sindorf and G. E. Maciel, "Silicon-29 CP/MAS NMR studies of methylchlorosilane reactions on silica gel," Journal of the American Chemical Society, vol. 103, no. 14, pp. 4263-4265, 1981.

[19] J. P. Nayak, Preparation and characterization of bioactive silica-based ceramics derived from rice husk ash [PhD Thesis], National institute of technology, 2010.

[20] K. E. H. K. Ishak and M. A. Ayoub, "Predicting the efficiency of the oil removal from surfactant and polymer produced water by using liquid-liquid hydrocyclone: comparison of prediction abilities between response surface methodology and adaptive neuro-fuzzy inference system," IEEE Access, vol. 7, pp. 179605-179619, 2019.

[21] S. Rahdar, M. Taghavi, R. Khaksefidi, and S. Ahmadi, "Adsorption of arsenic (V) from aqueous solution using modified saxaul ash: isotherm and thermodynamic study," Applied Water Science, vol. 9, no. 4, pp. 1-9, 2019. 